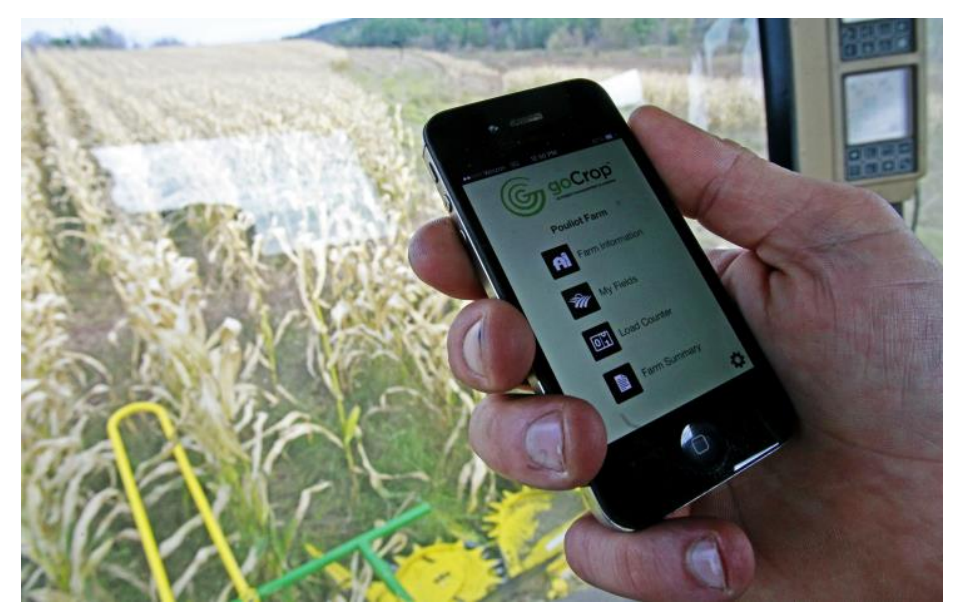

\title{
Espaço rural e espaço urbano: pluralidade conceitual e as tecnologias de informação e comunicação
}

\author{
Rural and urban spaces: \\ conceptual plurality and Information and communication technology
}

\author{
Cristiane Hengler Corrêa Bernardo ${ }^{1}$ \\ Juliana Correa Bernardes² \\ Silvia Cristina Vieira ${ }^{3}$
}

Resumo

Como proposição central, este artigo apresenta a seguinte problemática de pesquisa: como as tecnologias de informação e de comunicação podem auxiliar uma maior interação entre o espaço rural e o espaço urbano? Como objetivo geral, o artigo buscou compreender como as Tecnologias de Informação e de Comunicação podem ser utilizadas para a interação entre espaço urbano e rural. Especificamente, descreve a lacuna na definição das bases conceituais do que é espaço rural e urbano e observa o papel da comunicação, em específico das Tecnologias de Informação e de Comunicação, como mediador para uma compreensão destes espaços e das interferências mútuas que ocorrem. Como aporte metodológico utilizou a revisão bibliográfica e as teorias que conceituam campo e cidade, sobretudo nas discussões sobre conceitos intrínsecos aos fatores comunicacionais.

Palavras-chave: Espaço rural. Espaço urbano. Relação campo-cidade. Barreiras comunicacionais.

\begin{abstract}
As central proposition, this research sought to answer the following problem: how information and communication technologies can improve interaction between rural and urban areas? The main objective of this research was to understand how information and communication technologies can be used to improve interaction between urban and rural areas. Specifically, it describes the gap in defining the conceptual basis of what are the rural and the urban spaces, and notes the role of communication, in particular the Information and Communication Technologies as a mediator for understanding these spaces and its mutual interference. As methodological approach, a literature review was used as well as theories that conceptualize rural and urban spaces, especially the discussions of intrinsic concepts to communicational factors.

Keywords: Rural space. Urban space. Country - city relation. Communicational barriers.

\footnotetext{
${ }^{1}$ Professora do Programa de Pós-Graduação em Agronegócio e Desenvolvimento. UNESP - Campus Experimental de Tupã. E-mail: cristiane@tupa.unesp.br. Av. Domingos da Costa Lopes, 780 Jd Itaipu 17602-496 - Tupã, SP - Brasil

${ }^{2}$ Mestranda do Programa de Pós-Graduação em Agronegócio e Desenvolvimento. UNESP - Campus

Experimental de Tupã. bernardescj@gmail.com

${ }^{3}$ Mestranda do Programa de Pós-Graduação em Agronegócio e Desenvolvimento. UNESP - Campus Experimental de Tupã : tinavieiragomes@ hotmail.com.br

${ }^{4}$ Mestre em Agronegócio e Desenvolvimento pelo Programa de Pós-Graduação em Agronegócio e Desenvolvimento. UNESP - Campus Experimental de Tupã E-mail: tinavieiragomes@ hotmail.com.br
} 


\section{Introdução}

Este artigo parte do pressuposto de que a concepção do espaço rural e urbano apresenta uma profunda pluralidade ideológica. Tal importância, no entanto, depara-se com barreiras nas definições e conformidade conceitual do que é espaço rural e espaço urbano sob a influência da comunicação e da cultura local.

Desse modo, o processo conceitual promovido envolve relações nas esferas históricas, geográficas, socioeconômicas e culturais que se apresentam intrínsecas ao desdobramento da relação campo-cidade e têm passado por um conjunto de mudanças com impactos significativos nas relações apontadas.

Esta ocorrência tem motivado uma série de reflexões, mas que ainda são tratadas de modo compartimentado, tornando imperativo que tal discussão possa se dar de forma interdisciplinar, senão para se chegar a um consenso, pelo menos para avançar em termos conceituais.

Bernardo; Bernardes e Queiróz (2016) destacam que há várias discussões sobre o conceito de ambiente rural e ambiente urbano que "levam a uma tentativa de definição, baseando-se em história, política, cultura, economia e adventos da atualidade, em busca de uma compreensão simplificada destes ambientes”. No entanto, não se alcança um conceito conclusivo com exata diferenciação entre o que é o ambiente rural e urbano. Até porque não há consenso que permita tal conclusão, uma vez que os espaços atuais estão impregnados uns pelos outros.

A divisão censitária, realizada por dados do Instituto Brasileiro de Geografia e Estatística (IBGE), divulgado em 2010, situa mais de 160 milhões de brasileiros residindo na zona urbana e quase 30 milhões sediados na zona rural, representando apenas $16 \%$ da população total do país. Essa divisão toma como base os limites geográficos dos municípios que classificam a zona rural e zona urbana.

A situação distributiva, por si, já denota a preocupação que se deve ter com as interferências em ambos os espaços, uma vez que cada vez é menor a população rural, sendo que entre 2000 e 2010 a redução foi de dois milhões de habitantes. Um êxodo considerado, no mínimo, preocupante (IBGE, 2010).

Notadamente, a redução da população rural é inversamente proporcional ao incremento da população nas cidades, o que evidencia a tendência para o aumento da urbanização no país que já vem ocorrendo desde a década de 1950, com a ampliação da industrialização brasileira. 
No entanto, a integração entre o campo e a cidade é marcante e a população que permanece no campo passa a ter muitas das necessidades de quem reside na cidade para que, num cenário econômico e político, possa competir em condições mais equilibradas. A questão da escolaridade, do acesso às tecnologias de informação e de comunicação, ao transporte, à cultura, enfim, uma série de necessidades que nem sempre estão disponíveis no ambiente rural.

Pode-se constatar essa diferença ao se elencar os números de indivíduos maiores de 10 anos alfabetizados na zona urbana e na zona rural, respectivamente 128 milhões e 19 milhões, o que representa que na zona urbana, 80\% são considerados alfabetizados, enquanto que na zona rural esse percentual é 63\% (IBGE, 2010).

Dados da Pesquisa Nacional por Amostra de Domicílios (PNAD) revelam que em 2012, a taxa de analfabetismo das pessoas com 15 anos ou mais, residentes na zona rural, foi de $21,12 \%$. Apesar do número elevado, este valor foi $8,7 \%$ mais baixo que no ano 2000, sugerindo que os espaços rural e urbano estejam se tornando mais equilibrados.

Nesse contexto, torna-se importante compreender alguns fatores que podem colaborar com uma maior promoção interativa entre os espaços, assim como analisar as lacunas deixadas pela escassez conceitual do que é o cenário rural e o cenário urbano. Para tanto, este artigo buscou responder a seguinte problemática: como as tecnologias de informação e de comunicação podem auxiliar uma maior interação entre o espaço rural e o urbano?

Desse modo, o artigo teve como objetivo geral compreender como as Tecnologias de Informação e de Comunicação (TICs) podem ser utilizadas para a interação entre tais espaços. Especificamente, buscou-se descrever a lacuna na definição das bases conceituais do que é espaço rural e urbano e observar o papel da comunicação, em específico das Tecnologias de Informação e de Comunicação, como mediadora para uma compreensão destes espaços e das interferências que um sofre do outro.

Como aporte metodológico, este artigo buscou na revisão bibliográfica e nas teorias que apresentam as definições do campo e da cidade, apontamentos históricos, geográficos, socioeconômicos, culturais e nas discussões sobre fatores comunicacionais, ancorados nos costumes locais. Portanto, a pesquisa assume uma perspectiva de natureza qualitativa, que a partir dos conceitos já desenvolvidos e da reconstrução 
histórica do cenário rural e urbano, assume condições para promover discussões sobre como se constituem as definições plurais desses ambientes.

\section{As discussões conceituais dos espaços rural e urbano}

A percepção sobre os espaços rural e urbano permeia o histórico do desenvolvimento rural e os conceitos de divisão de terras, de modo que os poderes públicos municipais, que regem as ações fiscais com foco no recebimento dos impostos nesta esfera, elencam esta ação como de maior importância comparada aos seus aspectos geográficos, socioeconômicos e culturais. Ao encontro desta afirmação, Vieiro e Silveira (2011, p. 258) destacam que "as fronteiras entre o rural e o urbano tornaramse, cada vez mais, tênues e difusas".

Por sua vez, a reflexão sobre o desenvolvimento perpassa a escala global, nacional, regional e local. Sendo que a perspectiva do desenvolvimento rural se propaga pelo foco agrícola, ambiental e cultural. As transformações históricas levaram o enfoque territorial do desenvolvimento para além da cidade, o que permitiu o início da interrelação cidade-campo (VERDE, 2004).

Para Marques (2002), a definição do espaço urbano ocorre por meio de municípios, distritos, e da extensa ocupação de habitantes situados nele. Dessa maneira, o espaço urbano corresponde àquilo que não é rural.

Os estados estabeleceram definições oficiais para fins estatísticos e administrativos, colocando como variáveis para definição, os seguintes quesitos: discriminação por meio do patamar populacional; predomínio da atividade agrícola e demarcação político-administrativa.

Nota-se que as diretrizes políticas e econômicas limitam-se aos aspectos físicos e sociais, contribuindo para um conceito carente de considerações holísticas, fugindo da concepção sistêmica proposta pela interdisciplinaridade para análises de objetos complexos, como é o caso do ambiente, seja em qual esfera se der a análise.

Ao apontar a ausência da definição universal sobre o meio rural, Abromovay (2000) reflete sobre a contradição conceitual do rural e do urbano, destacando a fusão da cidade-campo:

O rural não é definido por oposição e sim na sua relação com as cidades. Por um lado, o meio rural inclui o que chamamos de "cidades" - em proporções que variam segundo as diferentes definições, abrindo caminho para que se enxergue a existência daquilo 
que entre nós, é considerado uma contradição nos termos: cidades rurais. [...] Se não há uma definição unitária do que significa "meio rural", o mesmo se pode dizer a respeito das "cidades"[...] As cidades definem-se com relação a suas funções e sua capacidade variável de imprimir à vida econômica de uma região. (ABROMOVAY, 2000, p. 2 e 16).

Argumenta-se que o meio rural e a cidade têm possibilitado uma nova construção de seu espaço, necessitando fazer um questionamento sobre as relações complexas que determinam o modo de vida no qual se inserem, desmistificando a fragmentação conceitual singularizada.

De acordo com Ferrão (2000), as realidades contemporâneas direcionadas às áreas rurais incluem espaços urbanos, suburbanos, rurais agrícolas e rurais não agrícolas, nos quais se articulam sistemicamente, por um lado de modo conflituoso e por outro de modo simbiótico, resgatando alguns componentes que caracterizaram a relação urbano-rural.

Ferrão (2000) constrói uma relação bastante interessante sobre o mundo rural "antigo" e o atual e suas relações simbióticas ou complementares com o espaço urbano. Para estabelecer essa relação parte-se da tetralogia na qual era organizada a estrutura arcaica rural que tinha como função principal - a produção de alimentos; como atividade econômica - a agricultura; como grupo social de referência - o campesinato, com seus valores, costumes e modos de vidas próprios e, por fim uma paisagem que refletia o equilíbrio entre o ambiente natural e as atividades humanas.

Na relação contemporânea, o espaço rural deixa de ser estritamente agrícola, uma vez que a partir da década de 1980, há uma nova perspectiva de olhar para os mundos rural e urbano, assim como no modo com que estes se relacionam. Como reflete Ferrão (2000), há o rompimento com dois elementos essenciais que compunham a tetralogia quais sejam: a função principal não mais, necessariamente, tem que ser a produção de alimento e a atividade não tem que ser exclusivamente a agrícola.

Essa nova visão quebra paradigmas seculares e estabelece a valorização da perspectiva não agrícola do mundo rural, partindo do conceito de patrimônio, em três sentidos: a renaturalização - focada na conservação e proteção da natureza; a busca por autenticidade - conservação de patrimônios históricos e culturais para proteção da memória e das identidades e a mercantilização das paisagens - valorização do turismo e do lazer (FERRÃO, 2000). 
Nessa mesma direção, Graziano (1993, p.11) já havia destacado a necessidade de quebra dos velhos paradigmas quando diz que,

É preciso ampliar essa velha noção de rural para além das atividades produtivas tradicionais (tais como culturas e criação de animais) e incluir no espaço agrário a produção de serviços (tais como lazer, turismo, preservação do meio ambiente, etc.) e de bens não agrícolas como, por exemplo, moradia e artesanato, incluído aí também as formas modernas de trabalho a domicílio, tão comuns nos países desenvolvidos. A nova e esperada onda de modernização no campo assentada na informática, na microeletrônica e na biotecnologia deverá ser ainda mais excludente que suas anteriores. (...) As evidências empíricas disponíveis no caso brasileiro, indicam que as melhorias das condições de vida e trabalho das populações rurais estão muito mais relacionadas com o 'nível de urbanização' que com o grau de desenvolvimento tecnológico alcançado pelas atividades agropecuárias de uma região.

Nesse sentido, ressalta-se a importância das Tecnologias de Informação e Comunicação para a aproximação entre os ambientes rural e urbano, de modo a colaborar com o processo de desenvolvimento local e regional.

Corroborando com estes apontamentos, Wanderley (2001) determina o espaço local, como o encontro entre estes dois mundos, no entanto, em cada um deles, suas particularidades não são anuladas, ao contrário, determinam a fonte da integração e da cooperação. O resultado desta aproximação não consiste na diluição de um destes espaços, mas na configuração de uma rede de relações que perpassa múltiplos planos, reiterando e viabilizando suas particularidades.

Rua (2005) considera que a cidade se infiltrou no campo e na sociedade rural. Não há contradições entre a cidade e o campo, desse modo, o estilo de vida urbana, a cultura e o capitalismo invadiram e absorveram o meio rural.

Já Santos (2002, p. 63) observa que “o espaço é formado por um conjunto indissociável, solidário e também contraditório, de sistemas de objetos e de sistemas de ações, não considerados isoladamente, mas como um quadro único no qual a história se dá”.

Entretanto, as constatações sobre os espaços urbanos e suas possibilidades baniram o espaço rural da posição de antítese e passou a considerar novos atores sociais, econômicos, políticos e culturais da modernidade. Neste caso, a globalização, oriunda da modernidade, passou por rearranjos nos processos de acumulação do capital que permeiam todas as dimensões da vida, inclusive o meio rural, buscando novas interações com o espaço urbano (LAUBSTEN, 2011). 
Tais interações estão presentes na própria dinâmica do sistema educacional. Dados do Censo Escolar da Educação Básica (BRASIL, 2016) revelam que no período entre 2008 e 2013 houve uma redução de cerca de 850 mil matrículas em escolas rurais. A tecnologia no campo, o êxodo rural e o transporte escolar oferecido pelo Estado 5 são fatores que contribuem para que os alunos provenientes do espaço rural estejam integrados nas escolas urbanas.

$\mathrm{O}$ acesso à infraestrutura que permite o funcionamento das Tecnologias da Informação e da Comunicação também foi relevante para a integração dos espaços e acesso à chamada modernidade. Como por exemplo, o Programa Federal de Universalização de Acesso ao Serviço de Distribuição de Energia Elétrica, conhecido como Programa Luz para Todos e instituído a partir da Lei 10.438/02. O Programa teve como meta o atendimento a dois milhões de famílias que não tinham acesso à energia elétrica. Após dez anos de existência, o Programa havia atendido mais de três milhões de famílias.

Os resultados do programa indicam a aquisição de eletrodomésticos e equipamentos, dentre os quais a recordista de compras foi a televisão, sendo que $81 \%$ das famílias adquiriram aparelhos, totalizando mais de 2,5 milhões de unidades. Nesse contexto, pode-se dizer que os meios de comunicação, sobretudo a televisão, que no Brasil ainda é a maior representante da comunicação em massa, abrem as porteiras da zona rural e levam impactos culturais, sociais e econômicos para o homem do campo.

O acesso a determinadas tecnologias de informação e comunicação, anteriormente restrita aos ambientes urbanos, traz para o campo a mudança de comportamento que aproxima cada vez o rural do urbano. Se por um lado as influências são positivas, principalmente no que se refere a elementos que possam auxiliar a produção agrícola e o bem estar das pessoas que habitam o ambiente rural, de outro a comunicação de massa pode "vender" uma imagem da zona urbana como modelo ideal, que se torna atrativo, sobretudo para o jovem, incitando, de certo modo ao êxodo rural e, consequentemente, pode causar as dificuldades de sucessão das propriedades rurais.

Ao mesmo tempo em que o morador da zona rural está, em grande parte das vezes, geograficamente distante das cidades, assiste, por meio das tecnologias de informação e comunicação, a realidade citadina que oferece oportunidades de trabalho, de estudo, de lazer, de bem estar, ofertadas pela mídia como ambiente ideal para se

\footnotetext{
${ }^{5} \mathrm{O}$ transporte escolar é direito garantido na Constituição Federal de 1988 e pela Lei de Diretrizes e Bases (Lei $n^{\circ}$ 9.394/96).
} 
“viver bem". É como se as TICs abrissem as porteiras da zona rural para um novo mundo que se avizinha.

Essa afirmação encontra base no conceito de aldeia global tecido por Mcluhan e Carpenter (1996, p.47), quando estes afirmam que "os meios eletrônicos de comunicação contraem o mundo, reduzindo-o às proporções de uma aldeia ou tribo onde tudo acontece a toda gente ao mesmo tempo: todos estão a par de tudo o que acontece e, portanto, no momento mesmo do acontecimento".

De acordo com Mota (2011, p.42), esses impactos decorrentes da globalização midiática são ainda mais perceptíveis no ambiente rural,

Até o início da década de 90, as famílias que viviam no campo enfrentavam grande isolamento midiático, principalmente em função das limitações geográficas, infraestruturais e financeiras. Com a expansão tecnológica e, principalmente, o crescimento das instalações de energia elétrica, os meios de comunicação tornaram-se acessíveis à grande maioria dos agricultores familiares, em especial as mídias de televisão e rádio. Com a chegada da TV aos lares rurais, o pensamento globalizado, até então pouco acessível ao camponês, passa a fazer parte de sua nova bagagem cognitiva e de suas cotidianidades.

A modernidade inseriu no campo as tendências urbanas, como a energia elétrica e as conexões via satélite, do mesmo modo que a população do campo levou para a cidade sua cultura, música, moda, culinária e vários costumes. Este fenômeno bloqueou suas definições isoladas, visto que a cidade e o campo dividem o mesmo espaço (FONSECA; SANTOS, 2009).

Além da percepção sobre os adventos da modernidade, Moreira e Hespanhol (2011) constatam que o local e o global, articulados e justapostos, mostram-se como uma das fragmentações do período técnico-científico e informacional e isso provem da velocidade da informação e da fluidez da comunicação.

Diante deste contexto, mesmo com as limitações conceituais, as características dos ambientes que determinam os espaços, vão além da configuração política - cidadecampo, agricultura-indústria, barreiras-desenvolvimento e antropologia-modernidade desdobra-se em tendências culturais inter-relacionadas e nas relações mediadas e incorporadas nas comunicações presentes nestas influências.

\section{Processo comunicacional: barreiras no contexto rural e urbano}

Entre as condições para tornar um conceito operacional, destaca-se a necessidade do amplo conhecimento das culturas e de seu modo de vida, sobretudo em 
como as pessoas se comunicam nestes ambientes e como elas enfrentam seus dilemas cotidianos, superando as barreiras comunicacionais; incluindo o vocabulário específico utilizado em cada espaço geográfico, seja ele no cenário rural ou no urbano.

Constata Bordenave (2002) que se tornam mais frequentes as pesquisas que definem como a comunicação pode contribuir para o desenvolvimento. Freire (2010) complementa essa constatação quando aborda a dimensão comunicativa como contexto de mudança social.

Neste sentido, a relação do rural e do urbano, apresentada nesta pesquisa, corrobora para este desenvolvimento apontado por Bordenave (2002) e reforçado por Freire (2010).

A interação dialógica entre o campo e a cidade, vai além da produção de alimentos, das relações sociais e profissionais. O processo comunicacional ocorrido nessa interação visa o compartilhamento de conhecimentos em uma via de mão dupla, construindo assim o fluxo bilateral de informações.

Torna-se importante ainda ressaltar que, como ajuíza Hall (1984), as relações sociais ocorridas durante o processo de comunicação abarcam não apenas emissor e receptor, mas também seus efeitos recíprocos entre os sujeitos comunicativos. E, portanto, há uma influência mútua entre os comunicadores rural e urbano.

Definir regras de comunicação caracteriza cada experiência pessoal e de cada sociedade, rural ou urbana, e confirma que a comunicação é ao mesmo tempo realidade e modelo cultural. Esta, por sua vez, recebe influência do meio em que é produzida e impacta e é impactada pelo receptor. Trata-se de uma relação inerente às relações sociais, uma vez que não há sociedade sem comunicação.

Reforça a afirmação anterior Wolton (2004, p.30), quando diz que na perspectiva intuitiva "comunicar consiste em compartilhar com o outro. Simplesmente não há vida individual e coletiva sem comunicação, não há seres humanos sem sociedade como não há sociedade sem comunicação".

Nesse sentido é que as Tecnologias da Informação e da Comunicação (TICs) representam instrumentos essenciais de aproximação entre os ambientes rural e urbano. Ainda é evidente a falta de acesso a determinados meios de comunicação e de informação no ambiente rural. Essa inacessibilidade não se restringe a novas TICs. Muitas vezes, em um país como o Brasil, com dimensões continentais, há regiões nas quais não há acesso nem mesmo à energia elétrica e em outras regiões nas quais torres para retransmissão de internet propiciam a utilização das mais modernas tecnologias. 
É fundamental um elo entre o rural e o urbano, visando o estreitamento das distâncias e a socialização das informações, num fluxo bilateral de comunicação. Partese da premissa de que este elo pode ser fortalecido por um processo comunicacional eficiente, minimizando barreiras existentes neste processamento e respeitando os saberes dos indivíduos inseridos nos diferentes espaços geográficos, independente do mapa conceitual plural que imprime características específicas para o universo rural e urbano.

De acordo com Santos (2003), as tecnologias de informação e comunicação contribuem para uma transformação que propicia novas visões do mundo, interações e quebra de paradigmas.

Nesse sentido, é fundamental destacar que a inclusão digital seja uma realidade presente também no ambiente rural, pois não basta apenas dar condições técnicas para que o campo disponha de tecnologias de comunicação e informação. É imprescindível que a inserção das TICs no ambiente rural venha acompanhada de uma inclusão digital efetiva.

Barros et al (2007) corroboram com essa afirmação ao dizerem que a inclusão digital constitui um elemento de destaque para as políticas dentro da sociedade da informação, sobretudo, em países com maiores índices de desigualdade social advindos da sua conformação histórica. Para tanto, é necessário oferecer formação para que sejam adquiridas competências necessárias às novas realidades sociais, econômicas e culturais da sociedade atual.

A necessidade aquisição de competências vai ao encontro do que Kroner e Weinstein (1994) já argumentavam quando falavam que as TICs, por si só, não são instrumentos de democratização, muito pelo contrário, elas podem acentuar as desigualdades sociais. Diante desse contexto, é importante a compreensão da relação cidade - campo e do uso das TICs, de modo a reduzir as assimetrias existentes entre as competências digitais dos habitantes da zona rural e da zona urbana.

\section{Considerações finais}

Como já foram descritas, embora com limitações conceituais que constituem o gap deste artigo, a pluralidade entre os conceitos do ambiente rural e urbano foi retratada pelas múltiplas visões que abarcam estes cenários, embasados em olhares de viés antropológico e moderno. Mesmo de forma embrionária, as divisões territoriais da 
cidade e do campo iniciaram, a partir do desenvolvimento, delimitações geográficas e fiscais destes espaços.

Partindo de uma análise antropológica, na qual foram observados fatos históricos, geográficos e políticos, percebeu-se que o viés conceitual se apoiava em aspectos limitados. Com o decorrer do desenvolvimento, avança-se para uma reflexão sobre as dimensões sociais e culturais presentes nestes espaços.

Já na contemporaneidade, passou-se a considerar o local e o global, no qual o advento da "Era Cibernética", ainda com restrições e barreiras no campo, disseminou a velocidade da informação, e aproximou o universo rural e urbano por meio das Tecnologias de Informação e Comunicação (TIC).

Numa visão contemporânea, as definições isoladas entre campo e cidade tornamse ainda mais complexas, pois cada vez mais se apresentam intrinsicamente ligadas. Os dois espaços encontram-se em intersecção, amparados por uma visão holística do todo e não mais a visão fragmentada.

Defende-se aqui, que a relação entre os sujeitos deva ser essencialmente dialógica, pois se parte do pressuposto de que a comunicação é um elo fundamental entre o rural e o urbano, visando o estreitamento das distâncias e a socialização das informações, num fluxo bilateral, que objetiva a aproximação dos espaços.

Parte-se da premissa de que este elo possa ser fortalecido por um processo comunicacional eficiente, minimizando barreiras existentes, e respeitando os saberes dos indivíduos inseridos nos diferentes espaços geográficos, independente do mapa conceitual plural que imprime características específicas para o universo rural e urbano. O processo comunicacional propicia a mediação de uma visão holística destes espaços, por meio da complexidade destes territórios.

Para tanto, torna-se fundamental tanto o acesso técnico às TICs, na perspectiva de sinal, rede elétrica, capacidade aquisitiva, quanto ao desenvolvimento de competências para que a inclusão digital possa ser um elemento concreto para a redução das desigualdades entre zona urbana e rural e de integração cultural, social e econômica.

\section{Referências}

ABRAMOVAY, R. Funções e medidas da ruralidade no desenvolvimento contemporâneo. Rio de Janeiro: IPEA, 2000. (Texto para Discussão, n. 702). Disponível em: <https://docs.google.com/document/d/1qx7gv2qgfSPUcO1vymH_bZc0 EVDatQgBYahepLpUQs8/edit> Acesso em 04 de abr. 2016. 
BARROS, S., ANDRADE, R.S., FERREIRA, F., NASCIMENTO, L., FERREIRA, F., SIMÕES, C., SILVA, H.P. e JAMBEOR, O. Digitalizando a Inclusão Social: o caso do Liceu de Artes e Ofícios da Bahia. In: JAMBEIRO, O., SILVA, H.P. e BORGES, J. (Org.). Cidades Contemporâneas e Políticas de Informação e Comunicações. Salvador (BA); Ed. UFBA, 2007.

BERNARDO, C.H.C.; BERNARDES, J.C.; QUEIRÓZ, T.R. O jovem urbano ruralizado: análise da comunicação no "mundo rural digital". Bauru: Revista Comunicação Midiática, 2016 (No prelo).

BORDENAVE, J.D. Além dos meios e mensagens. Petrópolis: Editora Vozes, 2002.

BRASIL. INEP Resumos técnicos. Disponível em http://portal.inep.gov.br/resumostecnicos Acessado em 15 de Junho de 2016.

MEC. RELATÓRIO EDUCAÇÃO PARA TODOS NO BRASIL 20002015. Disponível em http://portal.mec.gov.br/index.php?option=com_docman\& view $=$ download\&alias $=15774$-ept-relatorio-06062014\&Itemid=30192. Acessado em 15 de junho de 2016.

Relatório 10 anos do luz para todos. Disponível em http://www.mme.gov.br/10anosluzparatodos/index.html. Acessado em 14 de junho de 2016

FERRAO, João. Relações entre mundo rural e mundo urbano: evolução histórica, situação actual e pistas para o futuro. EURE (Santiago), Santiago , v. 26, n. 78, p. 123130, sept. 2000. Disponível em: <http://www.scielo.cl/scielo.php?script=sci_arttext\& pid=S025071612000007800006\&lng=es\&nrm=iso >. Acesso em e 06 abr. 2016.

FREIRE, P. Extensão ou Comunicação? Tradução Oliveira, R. D. $14^{\text {a }}$ ed. Rio de Janeiro: Editora Paz e Terra, 2010.

FONSECA, R. G; SANTOS, A J. C. dos. A influência de "modos de vida" rurais na cidade de Ituiutaba - MG. Trabalho apresentado no IV Simpósio Internacional de Geografia Agrária e V Simpósio Nacional de Geografia Agrária, realizado de 29 de outubro a 02 de novembro de 2009, p. 1-17. Niterói/RJ. Disponível em <http://www.uff.br/vsinga/trabalhos/Trabalhos\%20Completos/Rog\%E9rio\%20Geroline to\%20Fonseca.pdf>. Acesso em 16 mar. 2016.

GRAZIANO DA SILVA, José. Por um novo programa agrário. Revista Reforma Agrária, ABRA, n.2, vol. 23, maio/ago., p. 11, 1993.

HALL, Richard H. Organizações: estrutura e processos. Rio de Janeiro: PrenticeHall Do Brasil, 1984.

IBGE. Censo. Disponível em:< http://www. censo2010. ibge. gov. br/>.

KRONER, A. e WEINSTEIN, M. Data trash: the theory of the virtual class. [S.1]: St. Martin, 1994. 
LAUBSTEIN, C. F. A Ruralidade de ontem e hoje: uma análise do rural na comtemporaneidade. 2011. Revista Aurora. v. 4, n. 2, p. 93-102, Ago. 2011.

McLUHAN, M.; CARPENTER, E. 1996. Revolução na comunicação. Rio de Janeiro, Zahar Editores.

MARQUES. M. I. M. O conceito de espaço rural em questão. Terra Livre. São Paulo: AGB, n. 19, ano 18, jul. /dez. p. 95-102, 2002.

MOREIRA, E. V.; HESPANHOL, R. A. de M. O lugar como uma construção social. Formação: revista eletrônica do programa de pós-graduação em Geografia. n. 14, vol. 2 - UNESP, 2007. Disponível em: <http://www2.fct.unesp.br/pos/geo/revista /artigos/6_moreira_e_hespanhol.pdf>. Acesso em 2 abr. 2016.

MOTA, Alice Agnes Spíndola. A influência da televisão no desenvolvimento regional da zona rural no município de Palmas (TO). Fronteiras-estudos midiáticos, v. 13, n. 1, p. 41-57, 2010.

RUA, J. A. Ressignificação do rural e as relações cidade-campo: uma contribuição geográfica. Revista da ANPEGE (Associação Nacional de Pós-Graduação e Pesquisa em Geografia), Fortaleza, n. 2, p. 45-66, 2005. Disponível em: < http://anpege.org.br/revista/ojs-2.2.2/index.php/anpege08/article/view/81/41> Acesso em 17 jun. 2015.

SANTOS, M. Técnica e tempo, razão e emoção. São Paulo: Edusp, 2002.

SANTOS, M. Do giz à Era Digital. São Paulo: Zouk, 2003

VERDE, Valéria Villa. Territórios, ruralidade e desenvolvimento. Curitiba: Ipardes, 2004.

VIERO, V.C.; SILVEIRA, A. C. M. Apropriação de tecnologias de informação e comunicação no meio rural brasileiro. Cadernos de Ciência \& Tecnologia, Brasília, Brasília, DF, v. 28, n.1, jan./abr. 2011. Disponível em $<$ https://www.marilia.unesp.br/Home/Graduacao/PETBiblioteconomia/apropriacao-detic-no-meio-rural-brasileiro.pdf>. Acesso em 03 abr. 2016.

WANDERLEY, Maria de Nazareth Baudel. A ruralidade no Brasil moderno: por um pacto social pelo desenvolvimento rural. Una nueva ruralidad en América Latina, p. 31-44, 2001.

WOLTON, D. Pensar a comunicação. Brasília: Editora Universidade de Brasília, 2004.

Data de Recebimento: 20/07/2016

Data de Aprovação: 01/02/2017 


\section{Para citar essa obra:}

BERNARDO et al. Espaço rural e espaço urbano: pluralidade conceitual e as TICs. In: RUA [online]. $\mathrm{n}^{\circ}$. 23. Volume 1, p. 141 - 153 - e-ISSN 2179-9911 - Junho/2017. Consultada no Portal Labeurb - Revista do Laboratório de Estudos Urbanos do Núcleo de Desenvolvimento da Criatividade. http://www.labeurb.unicamp.br/rua/

Capa: Disponivel em <http://modernfarmer.com/2014/02/10-silicon-valley-agriculture$\underline{\text { start-ups/> }}$

\section{Laboratório de Estudos Urbanos - LABEURB}

Núcleo de Desenvolvimento da Criatividade - NUDECRI

Universidade Estadual de Campinas - UNICAMP

http://www.labeurb.unicamp.br/

\section{Endereço:}

LABEURB - LABORATÓRIO DE ESTUDOS URBANOS

UNICAMP/COCEN / NUDECRI

CAIXA POSTAL 6166

Campinas/SP - Brasil

CEP 13083-892

Fone/ Fax: (19) 3521-7900

Contato: http://www.labeurb.unicamp.br/contato 